\title{
THE MICROSPACE LAUNCHER: FIRST STEP TO THE FULLY AIR-BREATHING SPACE LAUNCHER
}

\section{F. Falempin, M. Bouchez, and M. Calabro}

A possible application for the high-speed air-breathing propulsion is the fully or partially reusable space launcher. Indeed, by combining the high-speed air-breathing propulsion with a conventional rocket engine (combined cycle or combined propulsion system), it should be possible to improve the average installed specific impulse along the ascent trajectory and then make possible more performing launchers and, hopefully, a fully reusable one. During the last 15 years, a lot of system studies have been performed in France on that subject within the framework of different and consecutive programs. Nevertheless, these studies never clearly demonstrated that a space launcher could take advantage of using a combined propulsion system. During last years, the interest to air-breathing propulsion for space application has been revisited. During this review and taking into account technologies development activities already in progress in Europe, clear priorities have been identified regarding a minimum complementary research and technology program addressing specific needs of space launcher application. It was also clearly identified that there is the need to restart system studies taking advantage of recent progress made regarding knowledge, tools, and technology and focusing on more innovative airframe/propulsion system concepts enabling better trade-off between structural efficiency and propulsion system performance. In that field, a fully axisymmetric configuration has been considered for a microspace launcher (10 kg payload). The vehicle is based on a main stage powered by air-breathing propulsion, combined or not with liquid rocket mode. A "kick stage," powered by a solid rocket engine provides the final acceleration. A preliminary design has been performed for different variants: one using a separated booster and a purely air-breathing main stage, a second one using a booster and a main stage combining air-breathing and rocket mode, a third one without separated booster, the main stage ensuring the initial acceleration in liquid rocket mode and a complementary acceleration phase in rocket mode beyond the air-breathing propulsion system operation. Finally, the liquid rocket engine of this third variant can be replaced by a continuous detonation wave rocket engine. The paper describes the main guidelines for the design of these variants and provides their main characteristics. On this basis, the achievable performance, estimated by trajectory simulation, are detailed. 


\section{INTRODUCTION}

By combining the high-speed air-breathing propulsion with a conventional rocket engine (combined cycle or combined propulsion system), it should be possible to improve the average installed specific impulse along the ascent trajectory and then make possible more performing launchers and, hopefully, a fully reusable one. A lot of system studies have been performed in France on that subject within the framework of different and consecutive programs [1]. Nevertheless, these studies never clearly concluded if a space launcher could take advantage of using a combined propulsion system or not.

As a matter of fact, past studies were performed sometimes by different teams with different tools and hypotheses, sometimes for particular purpose. For example, the purpose of system studies led in the framework of the National PREPHA program [2] was not to assess the feasibility of a fully reusable Single-StageTo-Orbit (SSTO) space launcher but only to determine some general technical requirements for the study of a scramjet system.

By another way, these studies used systematically a very conservative approach in terms of vehicle airframe configuration and it is doubtful that the best trade-off between air-breathing propulsion mode needs and the mandatory low dry mass for the vehicle and its propulsion system was obtained with the considered vehicle concepts.

What could be the individual impression or opinion one can have [3], it has to be noticed that a large worldwide effort is still under progress for developing the high-speed air-breathing propulsion technology in USA, Japan, Australia, Russia, India, China, and also in France [4-10].

In that context, a brief review of some of the main design issues of a future space launcher using combined propulsion leads to propose a focused approach for further new system studies which could take into account the progress made these last years in the related technologies.

\subsection{Single-Stage-to-Orbit}

A large part of the past system studies were focused on SSTO application. As a matter of fact, it is clear that the ultimate goal must be the development of an SSTO to finally make the access to space a daily routine with corresponding low cost and, then, to develop new unexpected markets.

It is generally accepted that a fully pure rocket-powered SSTO is not feasible with an achievable dry mass. By comparison, studies performed during the PREPHA program led to the conclusion that the combined propulsion could largely improve the feasibility of an SSTO if the air-breathing mode can be efficiently used on a very large flight Mach number range (i.e., from Mach 1.5-2 to Mach 10-12) [11]. 
Nevertheless, for such application, the payload mass is a very limited part of the total takeoff mass and the remaining uncertainties related to air-breathing mode performance and to achievable vehicle dry mass are of the same order of magnitude, making impossible to conclude on the real feasibility of such an SSTO launcher without structural breakthroughs [12].

By another way, due to the extreme sensitivity of the payload mass for a SSTO launcher, the development of an operational vehicle integrating a completely new and very complex propulsion system would correspond with an unacceptable development risk level.

\subsection{Two-Stages-to-Orbit}

On the contrary, it seems to be relatively easy to develop a Two-Stages-to-Orbit (TSTO) launcher with an air-breathing first stage.

Remark: it would be also possible to place the air-breathing mode on the second stage. But in this case, a large part of the problems related to the SSTO would remain (for example: heavy propulsion system placed into orbit, atmospheric reentry of an air-breathing vehicle) and would combine with the difficulty one can encounter for the flight back to the launching pad of a rocket powered first stage.

First studies led in France were considering different kinds of combined propulsion systems, for the first stage, with an air-breathing mode limited to Mach 6-6.5. They showed that a combined propulsion system was feasible but they also showed that this propulsion system did not improve the overall performance: the better average specific impulse being compensated by the increase in dry mass. Moreover, the pure rocket second stage remained not so easy to develop.

Other studies were performed to assess the interest of an extended airbreathing mode by considering a TSTO with a first stage operating up to Mach 10-12 by using a scramjet mode. Obviously, such a solution largely eases the development of the second stage. But it corresponds with a very complex first stage vehicle.

For all the previous studies, the staging was very close to the end of the air-breathing mode. Some complementary studies showed that it would be very interesting, from the point of view of payload mass/gross weight takeoff to fix the staging Mach number largely beyond the end of the air-breathing mode [13]. Nevertheless, that would correspond with an even more complex first stage vehicle.

In any case, one can assume that a TSTO would be feasible with pure rocket mode on the two stages (even if it can be necessary to add a limited speed airbreathing system to allow a direct and safe flight back to the launching pad 
for the first stage). Then, even if the combined propulsion can increase the performance in terms of payload mass/total takeoff mass, it would not avoid and in fact, it would reinforce, the difficulties related to the development and the operation of two complex vehicles. In these conditions, the development of a completely new propulsion system cannot make sense.

\subsection{Near Earth Orbit}

On the base of previous discussion, it appears that further system studies should address the concept that could be called "Near Earth Orbit" (NEO) [14].

Indeed, the use of a very limited expendable upper stage just avoiding to really place into orbit the vehicle can largely increase the payload mass (Fig. 1). For example, the generic mission for the SSTO studied within the PREPHA program was to reach a circular orbit at $500 \mathrm{~km}$. Eight metric tons of propellants were needed to circularize the vehicle orbit and then to deorbit. In the case of a NEO, the most part of this mass could be complementary payload improving the performance or could be considered as design margin reducing the development risk.

Even if the NEO is not a real SSTO, it would be designed as an SSTO and would take into account all the requirements related to the flight outside the atmosphere (attitude control, for example) and to the atmospheric reentry. Then, considering that the number of reusable space launchers will be limited and that these vehicles will remain some kinds of prototypes, it could be pos-

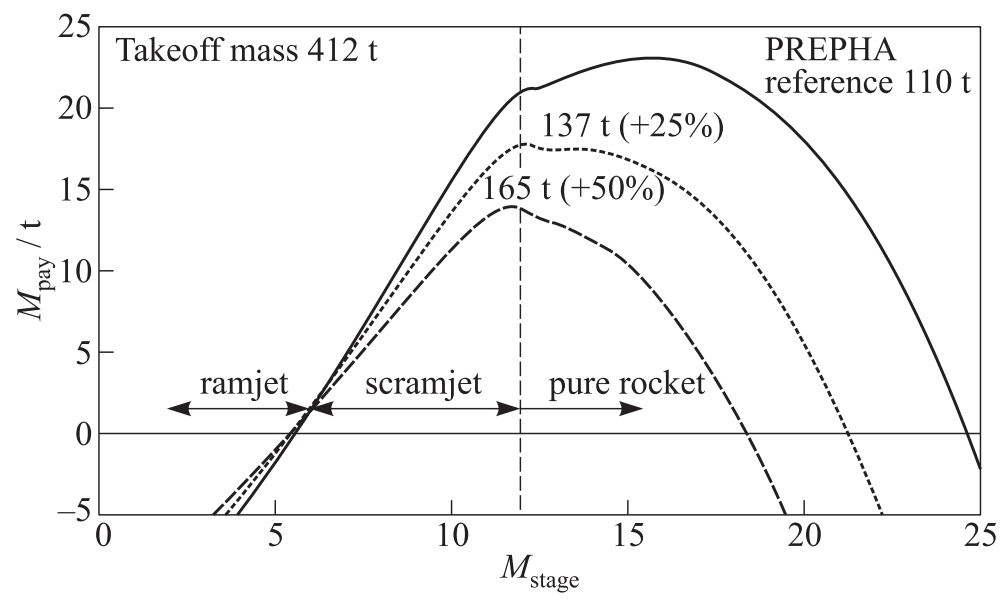

Figure 1 Effect of staging Mach number on payload for a TSTO using a low performance second rocket stage $\left(I_{\mathrm{sp}}=340 \mathrm{~s}\right.$ and dry mass $=12 \%$ of total mass $)$ 
sible to integrate step-by-step some performance to finally reach the real SSTO mission.

Remark: It has to be noticed that the design of the vehicle could take into account the possibility to really place the vehicle without payload in orbit in order to make possible the capture of a payload in orbit before returning on ground.

Such concept appears very attracting and is currently studied within MBDA France, especially in an axisymmetric shape.

\section{KEY TECHNOLOGY ISSUES}

The necessary technology development or risk reduction is described in [15]. This European point of view included minimum technology development proposal, taking into account the existing programs and facilities. The key technologies were once again addressed, sorted and the more critical ones were described.

The main issues will be detailed below with the illustration of the job made on the axisymmetric NEO launchers family. The feasibility of previously described application mainly depends on two key technology issues:

(1) capability to predict with a reasonable accuracy and to optimize the aeropropulsive balance (or generalized thrust-minus-drag); and

(2) development of needed technologies for the propulsion system as a low weight, high robustness fuel-cooled structure for the combustor.

For the second one, one example of promising advanced structure is given by the PTAH-SOCAR cooled technology [16]. The development of this technology seems well promising. For the current application, test with liquid hydrogen $\left(\mathrm{LH}_{2}\right)$ as coolant have to be planned to check the corresponding computations (many test series up to now were done with air, nitrogen, hydrocarbon, or bubbled kerosene as coolant). No particular problem is expected, considering the particular physical properties of $\mathrm{H}_{2}$, but $\mathrm{LH}_{2}$ has to be used on actual PTAH structures (first test for $\mathrm{H}_{2} / \mathrm{O}_{2}$ liquid rocket engine (LRE) are planned with gaseous hydrogen $\left(\mathrm{GH}_{2}\right)$ in the time to come on a demonstrator of nozzle extension [17].

\section{AEROPROPULSIVE BALANCE SENSITIVITY}

For an air-breathing propulsion system, the net thrust (i.e., the thrust which can effectively be used for compensating the drag and accelerating the considered 
vehicle including the propulsion system) is the difference between the thrust provided by the exit nozzle (momentum of accelerated hot gas coming from the combustion chamber) and the drag due to air capture by the inlet. As a matter of fact, atmospheric air has initially no speed. During capturing process, some energy has first to be paid to accelerate the incoming air in the upstream direction up to $40 \%$ to $75 \%$ of the vehicle speed. On the contrary, hot exhaust gas must be ejected through the nozzle in the rear direction at a speed exceeding flight speed (in vehicle reference).

This fact can be illustrated as follows:

- at flight Mach number 2, a net thrust of 1 is obtained by producing a thrust of 2 by the nozzle which compensates an air capture drag of 1 ;

- at Mach 8, a net thrust of 1 is obtained by a nozzle thrust of 7 while air capture drag is 6 ; and

- at Mach 12, a net thrust of 1 is obtained by a nozzle thrust of 12 while air capture drag is 11 .

Then, the higher the flight Mach number, the more sensitive the net thrust. At Mach 8, for example, an error of $5 \%$ on nozzle performance leads to a reduction of $35 \%$ in net thrust. At Mach 12, the same error will result in $60 \%$ net thrust reduction.

Then, it is more and more mandatory to optimize the integration of the propulsion system into the vehicle airframe, and vehicle and propulsion system components are operating in a much coupled way which would require testing the overall system to determine the global performance.

But, the higher the flight Mach number, the more difficult to simulate right flight conditions with on-ground test facilities. Generally, in such test facilities, air is heated up to total temperature before being accelerated through a nozzle to enter the test section at the right Mach number. Whatever the heating process may be, that generally leads to the creation of radicals, and very often some pollution into the incoming air, which can globally change the combustion process.

This problem is largely increased when heating process is based on precombustion (hydrogen, gaseous or liquid hydrocarbon fuel) and oxygen completion. In this case, chemical nature and thermodynamic characteristics of the incoming air are modified that creates change of ignition delay and modification of thermodynamics into the propulsion flow path.

By another way, for large and very large vehicles, some scaling effects are difficult (or impossible?) to solve. Then, a specific development methodology has to be defined by combining large-scale partial tests (possibly corresponding with very large, then expensive test facilities) and numerical simulation in order to be able to ensure design margins for the development of an actual full-scale 
system; the only one validation of this methodology accessible prior to the full scale development being acquired by numerical simulation.

The described above extreme sensitivity of the aeropropulsive balance, on the one hand, and the corresponding limited capability of ground test

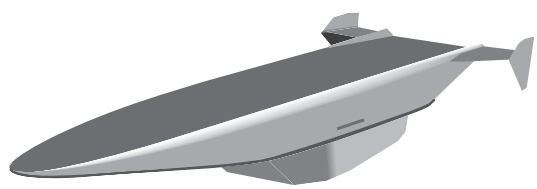

Figure 2 CAD view of LEA vehicle facilities to represent right flight conditions, on the other hand, make mandatory the definition of a specific on-ground development methodology coupling very closely experimental and numerical approaches.

In such a methodology, the in-flight performance can be predicted only by a nose-to-tail numerical simulation. Then on-ground test facilities will be used to perform partial test of vehicle and propulsion system components separated or coupled one to the another.

Beyond all current technology development works currently running in France [18] and on the base of previous acquired results, MBDA France and ONERA started a flight test program, called LEA, in January 2003 with the support of French Administration [19, 20]. In order to limit the cost, this flight test program would be performed with a 4-meter-long experimental vehicle having no technology demonstration purpose (use of existing technologies as often as possible) (Fig. 2). In the same view, this vehicle would be nonrecoverable, then

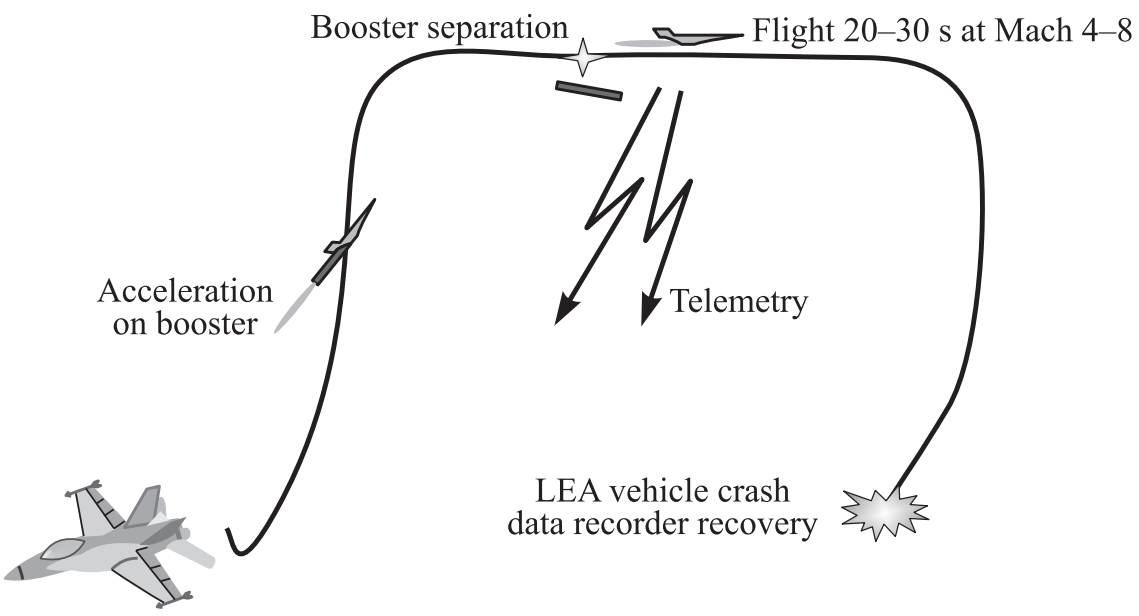

Figure 3 LEA flight testing sequence 
nonreusable. Specifically addressing the aeropropulsive balance, this flight test program is supposed to be performed in cooperation with Russian organizations.

The test principle consists in accelerating the flight experimental vehicle specimen using an air-launched booster up to the given test Mach number, chosen in the range from 4 to 8 . Then, after booster separation and stabilization, the experimental vehicle will fly autonomously during 20 to $30 \mathrm{~s}$. During this flight, the air-breathing propulsion system will be ignited during about $5 \mathrm{~s}$ with a fuel-to-air equivalence ratio variation (Fig. 3).

The vehicle would be specifically instrumented to give a precise evaluation of the aeropropulsive balance with and without combustion and to determine the contribution of each propulsion system component to this balance. All measured parameters will be transmitted to ground by telemetry and recorded with an onboard data recorder which will be recovered after the crash of the vehicle.

As explained previously and beyond a detailed understanding of the aeropropulsive balance, such a flight test program will give the opportunity to define, implement, and validate a development methodology applicable to any future operational development.

\section{PROPULSION SYSTEM CONCEPT}

As already mentioned, past studies performed in France demonstrated that combined propulsion could have an interest for space launcher only if the airbreathing mode can provide a significant part of the total speed increment.

For a TSTO, a limited part of the total speed increment given by the airbreathing mode will not make the launcher unfeasible but will not improve the performance (payload mass/total takeoff mass) by comparison with a full rocket system: reduction in needed fuel mass being compensated by the complementary dry mass of the air-breathing engine.

For a SSTO, it is clear that the complementary dry mass corresponding with the air-breathing mode and its integration into the vehicle will directly reduce the possible mass of payload. Then, the benefit provided by the air-breathing mode in terms of specific impulse improvement must be sufficient to compensate all these negative terms:

- large Mach number range of operation;

- high installed specific impulse allowing good acceleration level in the full air-breathing mode; and

- low dry mass.

Different types of air-breathing combined cycles were considered for the system studies performed within the framework of the PREPHA program $[1,11]$. 
These studies showed that the use of turbomachinery is not pertinent by comparison with systems based on ramjet. As a matter of fact, one can only take advantage of a turbine-based combined cycle in terms of specific impulse on a limited Mach number range (maximum up to Mach 6) while it corresponds with a very important increase of dry mass:

- the engine by itself is heavy; and

- its combination with a ramjet/scramjet system is very difficult and leads to complex and heavy air inlet consecutively ensuring the supply of a large air mass flow to two different air ducts.

At the contrary, a ramjet/scramjet (dual-mode ramjet - DMR) system can be used on a large Mach number range (up to Mach 12) and corresponds with more simple system using a single air duct, avoiding complex transition phase within the air-breathing mode and more limited induced dry mass addition.

A large effort has been led, mainly, in USA, on the Rocket Based Combined Cycle (RBCC) concept. Some system studies have been performed in France on that concept (particularly, in the framework of the PREPHA program). It has never been confirmed that such integration of the rocket mode into the airbreathing duct can improve the global performance. As a matter of fact, in order to obtain a ramjet effect at low Mach number (between 0 and 1.5-2) and then improve the specific impulse, one must reduce rapidly the thrust of the rocket mode (very rich propellants mixture). But this action dramatically reduces the global thrust and then the vehicle specific impulse (acceleration capability). Then, it appears preferable to use the rocket mode at full power (eventually without any ramjet effect) up to the minimum Mach number for which the air-breathing mode is able to provide alone a sufficient thrust to obtain an improved vehicle specific impulse. By another way, if one tries to integrate into the air-breathing duct the rocket engines ensuring the final acceleration, that leads to strong integration constraints limiting the achievable performances for the air-breathing mode, particularly, at high Mach number (supersonic combustion), and generates new difficulties related to the thermal sizing of the air-breathing combustion chamber. Finally, such an RBCC system makes more complex the attitude control during the flight outside the atmosphere, rocket engines thrust being not easily directed to the vehicle center of gravity.

\section{NEED OF A VARIABLE GEOMETRY CONCEPT FOR DUAL-MODE RAMJET}

As a very large flight Mach number range must be considered for the DMR (i.e., 1.5 to 12 ), a variable geometry is mandatory to provide the best acceleration capability of the air-breathing mode. 


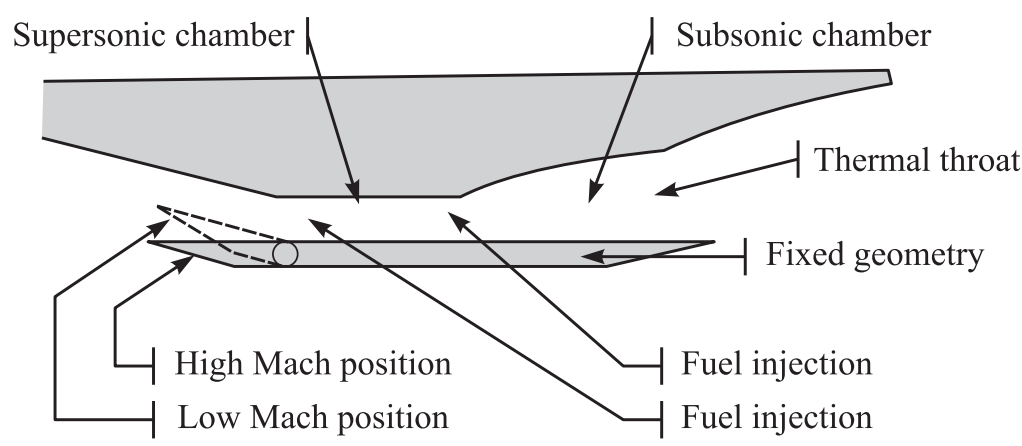

Figure 4 Fixed geometry concept of PREPHA engine

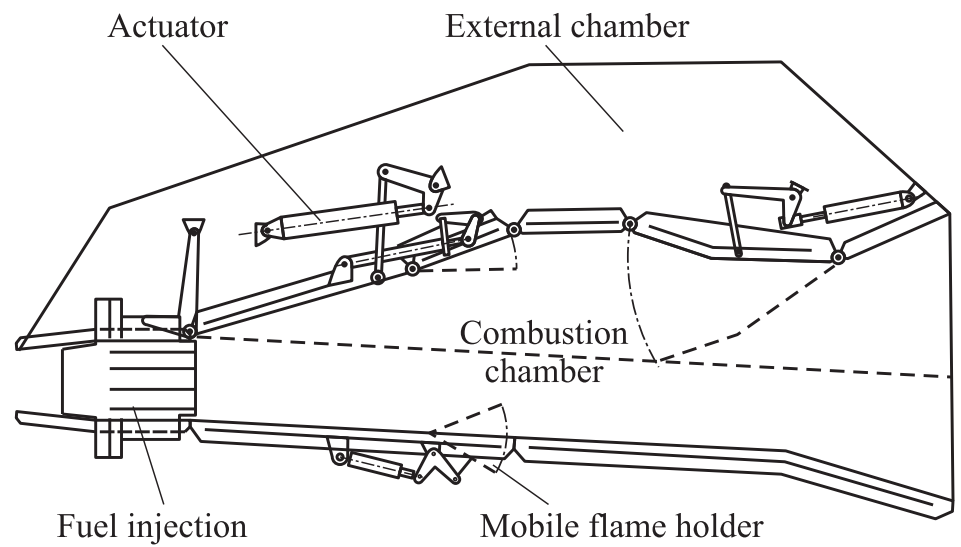

Figure 5 Variable geometry of WRR engine

A fixed-geometry combustion chamber associated to a variable capture area air inlet was considered (Fig. 4). But, due to the fixed minimum section of the air inlet (equivalent to the fixed section of the combustion chamber entrance), the thrust was limited at low Mach number because of the blockage of incoming air. Moreover, if one tries to maintain the air inlet capture area within the bow shock up to the maximum Mach number of the air-breathing mode, the air inlet size is limited and consecutively, the available thrust reducing the vehicle specific impulse.

A different concept has been developed with the Moscow Aviation Institute (MAI). This concept, called WRR (wide range ramjet), has a fully variable geometry - air inlet + combustion chamber (Fig. 5). Then, performances can be increased by comparison with the previous concept as it is shown in [21]. 


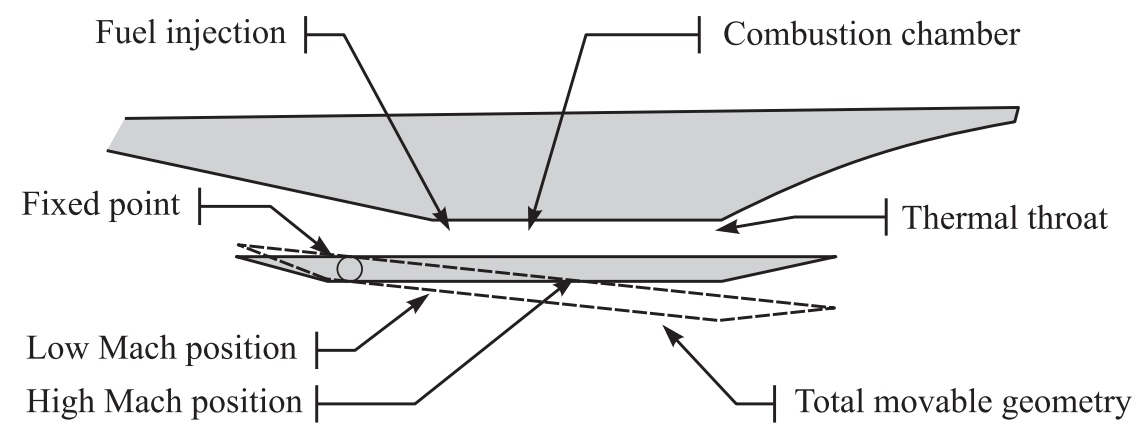

Figure 6 Variable geometry of PROMETHEE engine

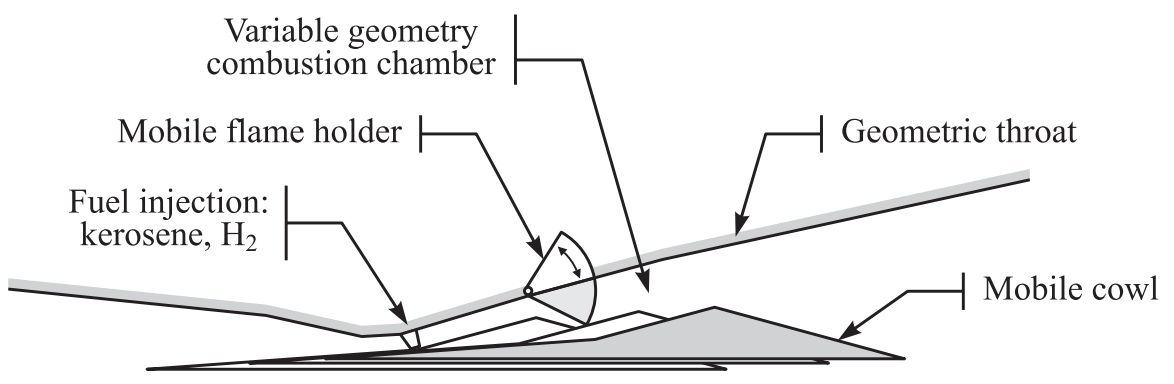

Figure 7 Variable geometry of PIAF engine

Nevertheless, this concept has the same limitation as the PREPHA concept (i.e., fixed minimum section of the inlet). Then, one cannot take all the benefit of the complexity related to a fully variable geometry system.

Other concepts have been studied which consist in modifying in the same time the minimum section of the air inlet and the geometry of the combustion chamber by using a simple movement of the engine cowl. PROMETHEE program was focused of a rotating cowl concept (Fig. 6), while PIAF studies, performed with MAI, are focused of a translating cowl (Fig. 7).

For such concepts, having at disposal a variable minimum section for the air inlet avoids the need of a large variation of the air inlet capture area (i.e., increase when the Mach number increases). Then, the limitation of engine size due to the bow shock is reduced and air-breathing engine can be larger at low Mach number providing high thrust level and then better vehicle specific impulse. In these conditions, it is possible to switch to air-breathing mode earlier increasing subsequently the overall performance.

In the example in the present paper, the annular DMR engine has the following performance with flight Mach number (Fig. 8). 


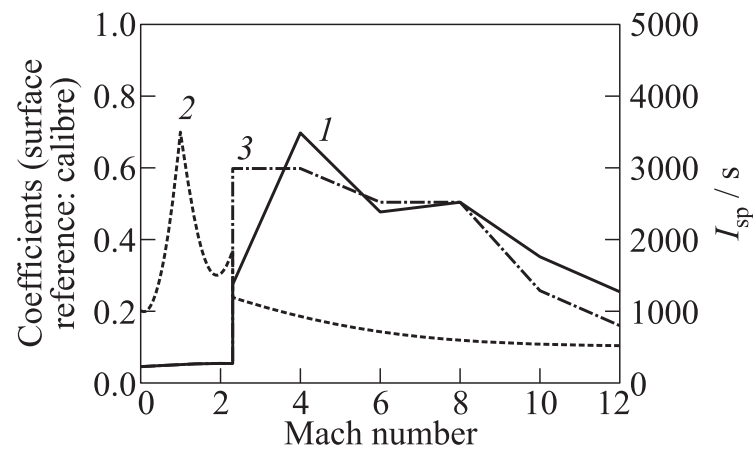

Figure 8 Expected performance of DMR: $1-C_{\mathrm{PI}} ; 2-C_{X}$; and $3-I_{\mathrm{sp}}$

In Fig. 8, the fuel specific impulse of the engine is given on the right scale. The left scale corresponds to the dimensionless coefficients (related to the calibre area): $C_{\mathrm{PI}}$ is the thrust coefficient while $C_{X}$ is the drag coefficient (ramjet streamline tube excluded). These values correspond to the "variant 1 " axisymmetric launcher presented hereafter.

\section{AIR-BREATHING ENGINE INTEGRATION}

Dual-mode ramjet has obviously the drawbacks of its advantages: a low specific thrust associated with a high specific impulse. The size of the required engine is then quite big, and its weight is about $1000 \mathrm{~kg}$ per square meter of air inlet capture area (a benefit of $30 \%$ can be expected by using ceramic composite materials [22]).

Most of the current launcher projects have quite conventional shapes and the need to integrate a large air-breathing propulsion system leads to very low structural efficiency for the flat airframe which is mainly a pressurized fuel tank.

However, other concepts could be studied to try to ensure better tradeoff between air-breathing propulsion system needs and airframe structural efficiency [14].

The first example of these possible vehicles consists in twin axisymmetric fuel tanks, which are linked by a large two-dimensional (2D) air-breathing propulsion system while the rocket engines are placed on the base of cylindrical fuel tanks (Fig. 9).

This configuration lends itself a very large, fully variable geometry airbreathing system, which has no limitation at low Mach number and then can 


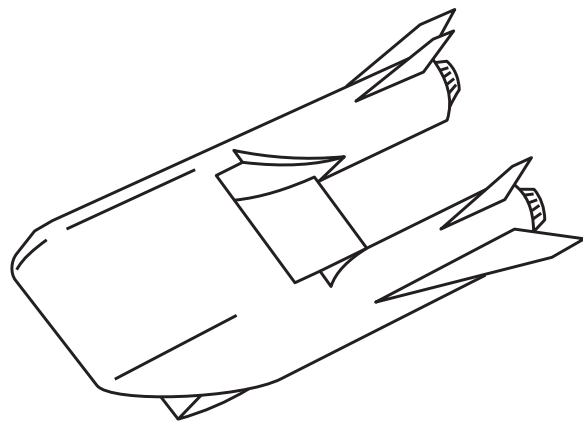

Figure 9 Twin fuel tank concept

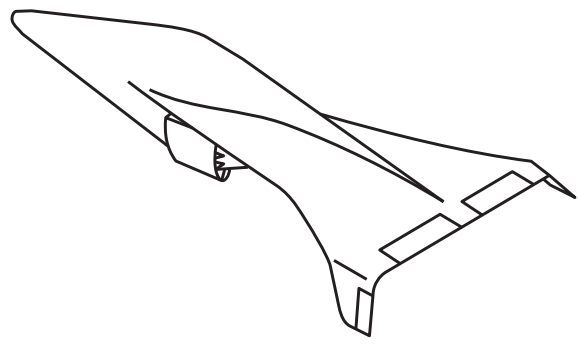

Figure 10 Double cone airframe concept

provide a very high level of thrust. The upstream position of the air-breathing mode make possible an inversed single expansion ramp nozzle (SERN) that contributes to the lift at low Mach number rather than increasing the apparent weight. This said, the problem of large base drag created by the two rocket engines still remains and the reentry phase (air inlet closed, of course) is questionable.

Another concept can be proposed as shown on Fig. 10. It is based on a double cone fuselage, which corresponds with a very good structural efficiency. The air-breathing engine is semiannular and takes advantage of a very large air capture section provided by the cone. It can be considered as a series of relatively small modules, which could be more easily tested on ground. The rocket mode can be integrated in the



Figure 11 Fully axisymmetric concept external part of the SERN. The wing is designed to provide protection of the propulsion system during the reentry phase $\left(180^{\circ}\right.$ vehicle turn before reentry). Telescopic aerodynamics could provide performing precompression while allowing a large nose radius during the reentry phase.

A completely axisymmetric concept can be also proposed as shown in Fig. 11. This concept will be discussed hereafter in more detail. Rocket engines are placed in the downstream cone which constitutes the external part of the SERN. It is then very easy to control the vehicle also during the flight outside the atmosphere while taking advantage of maximum expansion. The movable cowl of the air-breathing engine can be moved upstream to the maximum diameter of 
the fuselage in order to create a circular wing on the back of the vehicle, allowing to land horizontally after reentry and deceleration phases (already designed for very large thermal loading). Such a concept leads to a very large engine (2 to 2.5 times larger than that of PREPHA for the same vehicle size). Then, the air-breathing phase is very efficient and can be performed with a high slope angle, which dramatically reduces the duration of the atmospheric flight (Mach 0 to 12 in $250 \mathrm{~s}$ instead of $1100 \mathrm{~s}$ for the PREPHA generic vehicle) and then improves the overall efficiency and, maybe, relaxes the constraints for the sizing of the thermal protection system.

Beyond these technology development efforts, the need was also clearly identified to restart system studies taking advantage of recent progress made regarding knowledge, tools, and technology and focusing on more innovative airframe/propulsion system concepts enabling better trade-off between structural efficiency and propulsion system performance.

\section{AXISYMMETRIC AIR-BREATHING LAUNCHERS FAMILY STUDIED}

In that field, a fully axisymmetric configuration has been considered for a reusable microspace launcher $(10 \mathrm{~kg}$ payload). The vehicle, based on a double cone fuselage providing good structural efficiency, is constituted by a main stage powered by air-breathing propulsion, combined or not with liquid rocket mode. A "kick stage," powered by a low-performance solid rocket engine provides the final acceleration (NEO concept) (Fig. 12).

The air-breathing engine is annular and can also be constituted by a series of modules, each easily testable on ground (in any case, corresponding to a limited

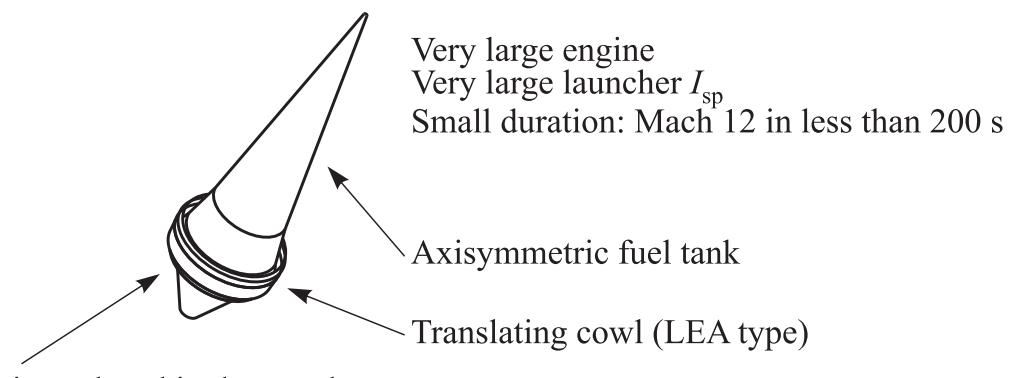

Rocket engines placed in the nozzle

(aerospike - possibly CDWRE)

Figure 12 Axisymmetric NEO concept 
scaling effect by comparison with possible ground testing). This engine has fully variable geometry, one using a concept derived from the LEA engine. Taking advantage of the translating movement of the cowl, the rear part of the engine can be closed to ensure a safe reentry on the back using the aerospike nozzle as blunt nose providing the needed thermal protection.

A preliminary design has been performed for different variants: one using a separated booster and a purely air-breathing main stage, the second one using a booster and a main stage combining air-breathing and rocket mode, the third one without separated booster, the main stage ensuring the initial acceleration in liquid rocket mode and a complementary acceleration phase in rocket mode beyond the air-breathing propulsion system operation (Fig. 13).

On this basis, performance assessment has been carried-out by means of trajectory simulation. The main conclusions are as follows:

- The very large air-breathing engine delivers a very large thrust level.

- This thrust level provides a very high acceleration capability and then a very good launcher specific impulse.

- It also allows starting the air-breathing mode very early (at about Mach 1.5) reducing the needed on-board oxidizer mass, then the corresponding tank mass.

- The acceleration capability allows reaching Mach 12 in less than $200 \mathrm{~s}$ (to be compared with 1000 to 1200 s needed with an airplane-like vehicle (PREPHA vehicle, for example).

- Then, the air-breathing mode, and consecutive trajectory in the atmosphere, does not lead to thermal protection oversizing.

- The large air-breathing engine corresponds with a limited dry mass increase as it is mainly constituted by a short annular cowl.

- Finally, there will be a clear advantage in replacing the LRE of this third variant by a continuous detonation wave rocket engine (CDWRE) for which integration will be largely easier and more efficient (including a very simple way to control the thrust vector and to close the engine for the reentry phase) [23].

\section{$7.1 \quad$ Variant 3 (Near Earth Orbit)}

This variant shown in Fig. 13 is the most advanced and performing one. It is a NEO launcher without separated booster: the main stage is ensuring the initial 


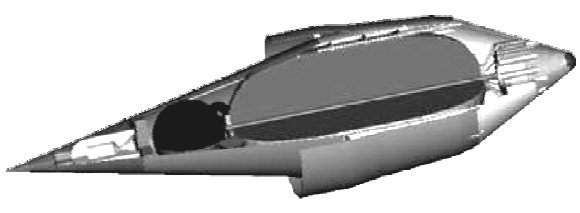

Figure 13 Axisymmetric NEO microspace launcher - internal layout of variant 3

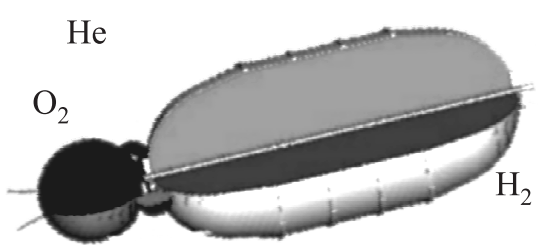

Figure 14 Tanks of variant 3

acceleration in liquid rocket mode (here, $\mathrm{H}_{2} / \mathrm{O}_{2}$ ) and a complementary acceleration phase in rocket mode beyond the air-breathing propulsion system operation. Finally, the LRE of this third variant can be replaced by a CDWRE.

The tanks can be linked together before to be introduced in the main stage CMC structure (Fig. 14).

All the previous elements lead to the feasibility of a reusable main stage with a staging at Mach 14.5 corresponding to a 8.5-meter long, 3.0-meter diameter vehicle with a gross takeoff weight of about 4.5 metric tons, able to place in a 250 -kilometer circular orbit a payload of $10 \mathrm{~kg}+30 \mathrm{~kg}$ of avionics.

The current CAD layout allows to built such a launcher in a step-by-step approach and replace the 'rear' cone by an interstage to solid propellant booster during develompemnt qualification, if needed, or by a CDWRE in the same geometry with improved performance. This modular rear part can be checked separately on ground before its integration on the vehicle.

\subsection{Variant 1 (Multistage)}

As the opposite, this simpler but less efficient variant is using a separated booster and a purely air-breathing main stage (Fig. 15). There is no LOX on-board.

The TVC booster as well as the solid propellant kick-stage have been designed by the The Inner Arch with existing technology and Ariane 5 type propellant.

The current design does not include overlapping between the booster and the DMR operation (for example, between Mach 1.5 and 2.5).

The takeoff weight is $5800 \mathrm{~kg}$ (can be reduced by more than $300 \mathrm{~kg}$ at least if overlapping is used). The booster uses $3.1 \mathrm{t}$ of solid propellant.

The mass at the ignition of the ramjet, after booster separation, is $2124 \mathrm{~kg}$ (Fig. 16).

The maximum acceleration is between $5.5 \mathrm{~g}$ and $6 \mathrm{~g}$, in all the modes, including the DMR one. 


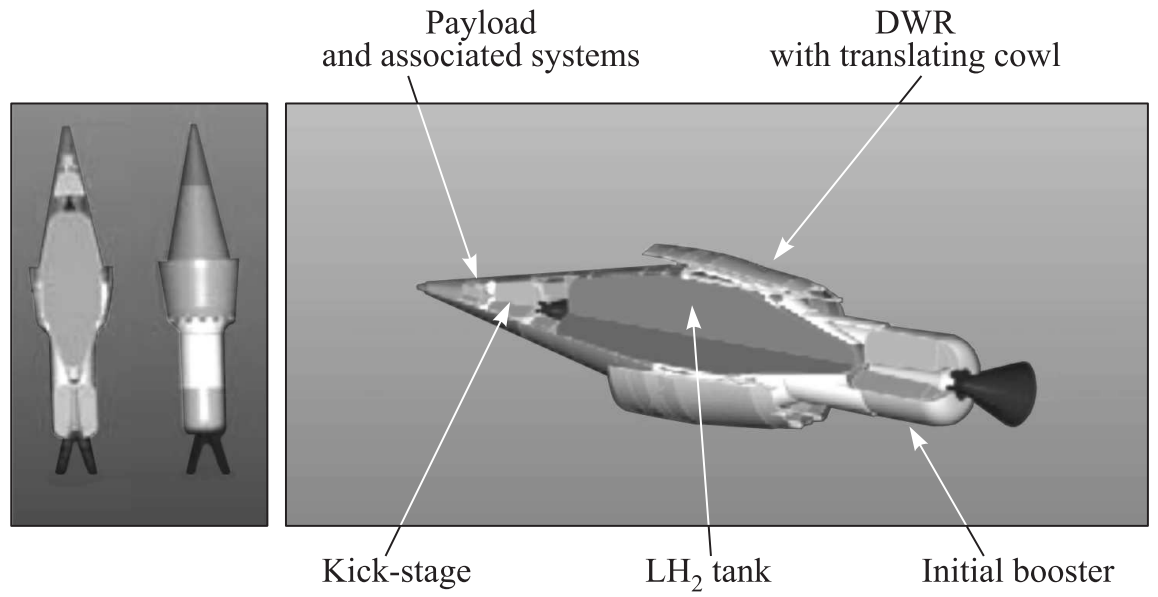

Figure 15 Variant 1, CAD view

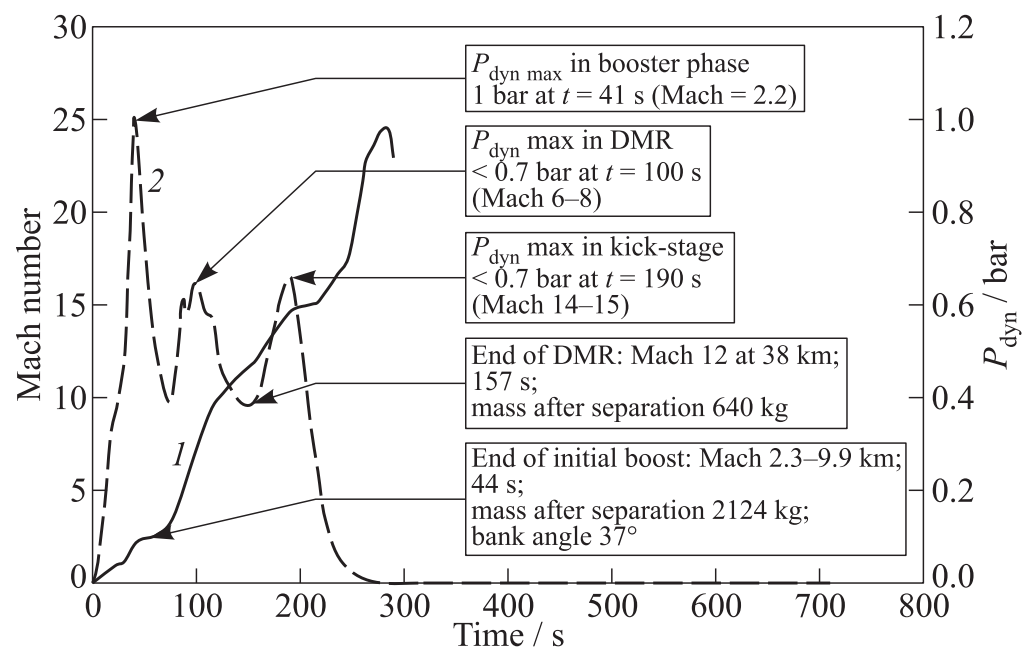

Figure 16 Variant 1 trajectory, Mach number (1) and dynamic pressure (2) vs. time from launch

\subsection{Variable Geometry of Annular Dual-Mode Ramjet}

The DMR has an annular stream, with one degree of freedom, but as the concept of PIAF and LEA, is able to manage enough area variation between Mach 2 and 12 (Fig. 17). It is also possible to use the cowl translation to close the 

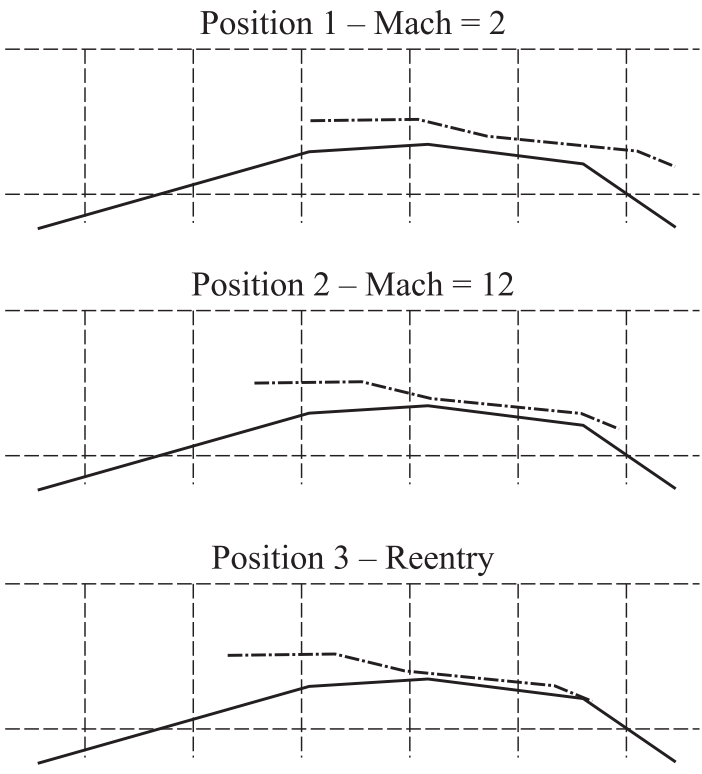

Figure 17 Variable geometry of annular DMR

rear part and ensure a possibility or pseudoreentry after an in-space 180 degree rotation. That is why the radius of the 'upper' - 'front' part of the cone is small (good air capture and limited heat fluxes during ascent) and the 'rear' part is quite blunt (reentry capability).

The performance of the different variants are investigated using onedimensional (1D) analysis, based on experimental results of ground-tested DMR. Air mass flow is computed using three-dimensional (3D) Navier-Stokes computations, depending on chosen shape (including leading-edge feasible radius), inlet

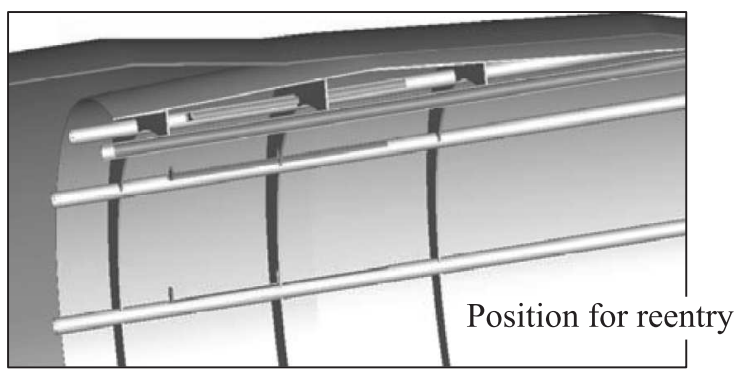

Figure 18 CAD view of cowl movability (variant 3) 


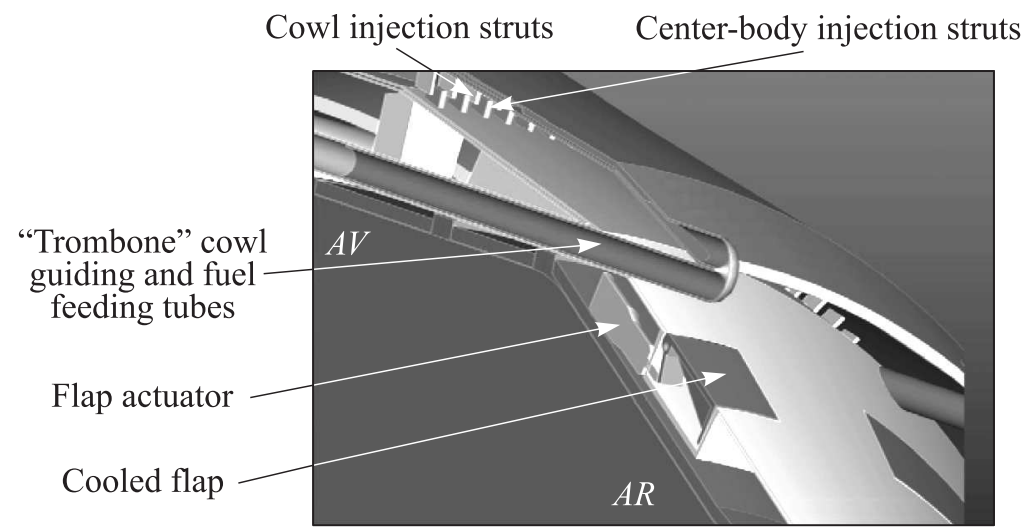

Figure 19 Details on DMR injection and movable parts (variant 1)

geometry, cowl position, etc. generally the angle of attack is assumed to be equal to zero.

Some nose-to-tail 3D Navier-Stokes computations have been made, to estimate the effect of small but nonequal-to-zero angle of attack, especially on stability. The geometric solution is then integrated on a simplified but complete CAD model, in order to check the possible layout, the corresponding volumes, masses, and inertia characteristics.

The actual possibility of realizing such movability has to be checked (Fig. 18). After several studies at a very-preliminary stage, a solution has been chosen for the current advanced studies.

The cowl is actuated by applying simple "trombones" that are used also for fuelling the cowl injectors.

The same approach has been done on the layout of variant 1 (Fig. 19).

\section{STABILITY AND CONTROL}

The control of the launcher is DMR mode can be done using the local injection modification or flaps (can be used in combination or not).

The last solution is presented in Fig. 20.

It could be possible to vary, on a given angular part of the flowpath, the injection. This possibility was introduced on the CAD layout of variant 1 on $1 / 12$ or $1 / 3$ sectors, on the body injection struts only (see Fig. 19). Control valves are put very close to these injection ports, to be able to neglect the corresponding inertia and time response. As sketched below, it would be possible to control the vehicle in DMR operating (Fig. 21). 


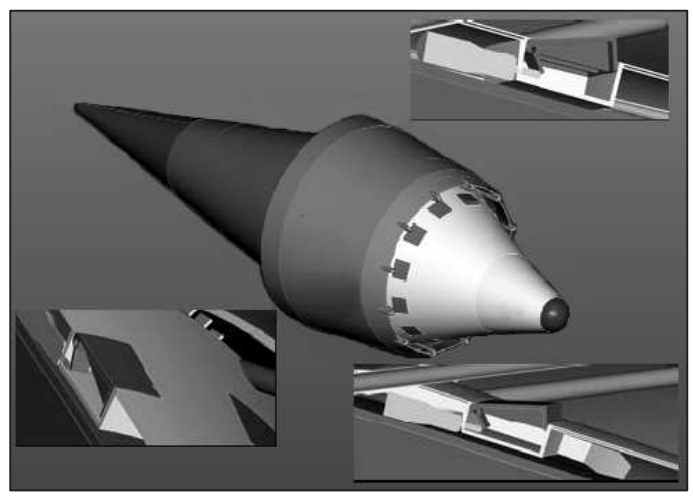

Figure 20 Flaps for possible control in DMR mode

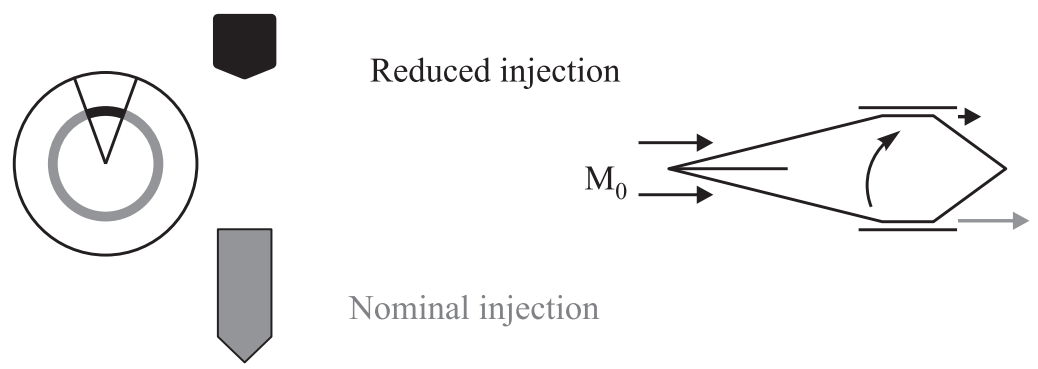

Figure 21 Control with differential injection

Nose-to-tail 3D computations have been undertaken first to estimate the effect of a small angle of attack on the stability but also to investigate what could be the effect of modifying the injected equivalence ratio on a given sector $\left(30^{\circ}\right.$ or $120^{\circ}$, for example). Illustration is given below for Mach 12 computations (Fig. 22).

The entrance flowfield is then used in a 3D combustion chamber computation (here, with the same code) for a sector between two struts (elementary sector) with a given and variable equivalence ratio (Fig. 23).

\section{THERMAL STRENGTH}

The cooled parts, mainly, the DMR, the aft nozzle, and - in existing - the LRE are assumed to be realized based on the CMC PTAH-SOCAR technology. The $\mathrm{H}_{2}$ mass flow is computed (using NANCY engineering code [24] and PTAH 


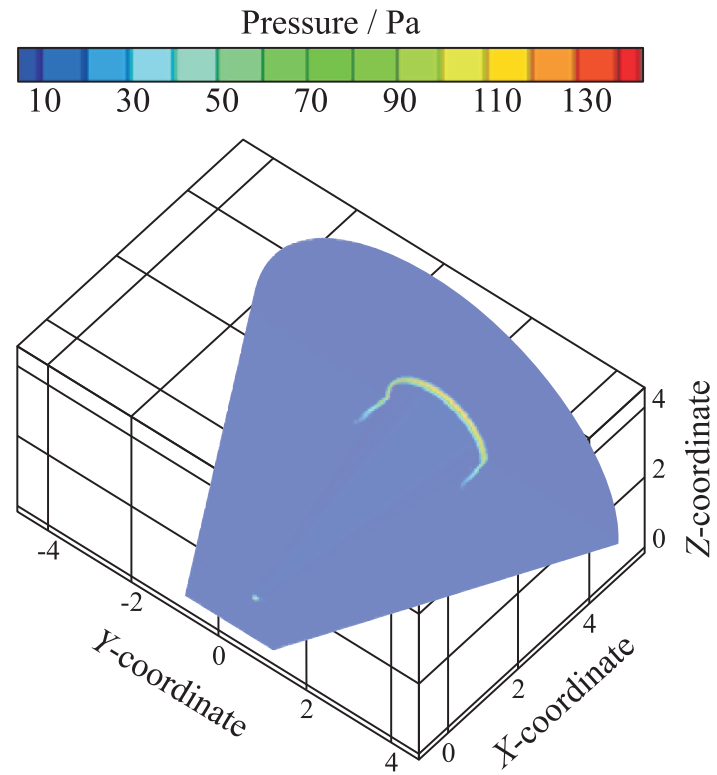

Figure 22 Three-dimensional Navier-Stokes computations (forebody and intake). (Refer Falempin et al., p. 589.)
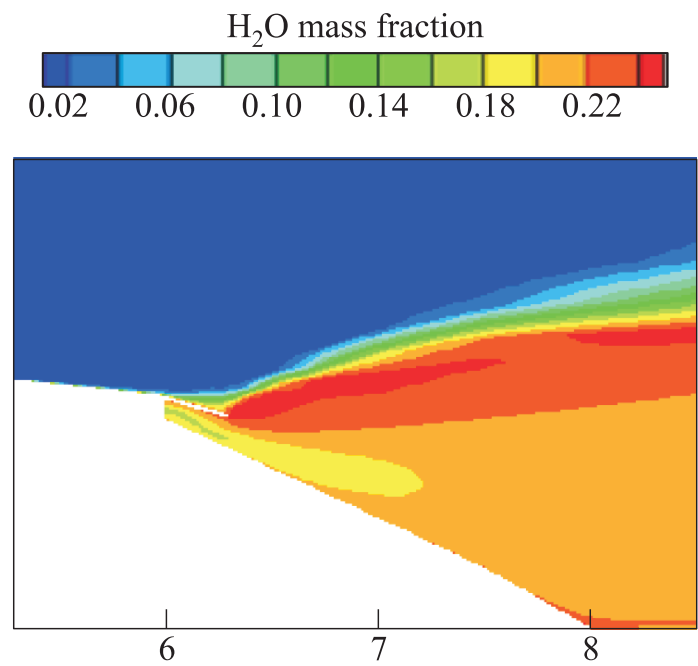

Figure 23 Nose-to-tail 3D computations (nozzle part). (Refer Falempin et al., p. 589.) 
models [17]) to be sufficient to cool the corresponding areas. Part (10\%) of the $\mathrm{LH}_{2}$ can be used to drive the turbopump, if any.

The uncooled part takes benefit of the used materials (CMC able to operate up to $1800 \mathrm{~K}$ ) as well as the short ascent time (200 s, typically). The convective/radiative equilibrium temperature on the fuselage is never reached during the ascent trajectory. On-the-shelf solutions can be used, as shown by $1 \mathrm{D}$ transient conduction. The corresponding mass and thicknesses have been taken into account in the CAD layout.

\section{CONCLUDING REMARKS}

The ramjet/scramjet concept constitutes the main air-breathing propulsion system which can be used in a very large flight Mach number range up to Mach 10-12 and then could allow developing future fully reusable space launcher and military systems.

Beside international activities, mainly, in USA and Japan, a permanent research and technology effort has been pursued in Europe since twenty years. Today, the effort led in France aims at addressing the two key technology issues which are the accurate prediction of the aeropropulsive balance of an airbreathing vehicle flying at high Mach number and the development of hightemperature structures for the combustion chamber able to withstand the very severe environment generated by the heat release process while ensuring reliability and limited mass and should allow to conclude on the feasibility and interest of the two possible application within the next five to six years $(2012 / 2013)$.

\section{ACKNOWLEDGMENTS}

The work presented here was done with partial support of CNES (special mention to Raymond Bec).

\section{REFERENCES}

1. Falempin, F., Ph. Novelli, P. Hendrick, and A. Souchier. 2002. Air breathing/rocket combined cycle propulsion efforts in Europe. AAAF-2002-268. Versailles.

2. Falempin, F., D. Scherrer, G. Laruelle, Ph. Rostand, and G. Fratacci. 1998. French hypersonic propulsion programme PREPHA - results, lessons and perspectives. AIAA Paper No. 98-1565. 
3. Lentsch, A., R. Bec, F. Deneu, Ph. Novelli, M. Rigault, and J.-M. Conrardy. 2003. Air-breathing launch vehicle activities in France - the last and the next 20 years. AIAA Paper No. 2003-6949.

4. Falempin, F. 2002. High-speed air breathing propulsion French activities. AIAA Paper No. 2002-5232.

5. Le, J., W. Liu, Y. Tan, and W. He. 2003. Performance study of model scramjet with fuel of kerosene in pulse facility. AIAA Paper No. 2003-6936.

6. Hutt, J. 2003. Space launch roadmap. AIAA Paper No. 2003-6941.

7. Boudreau, A. 2003. Status of the air force HyTech program. AIAA Paper No. 20036947.

8. Fujii, K., T. Nakamura, H. Kawato, and S. Watanabe. 2003. Concepts and studies of flight experiment vehicles for reusable space transportation system. AIAA Paper No. 2003-6984.

9. Boyce, R., S. Gerard, and A. Paull. 2003. The HyShot scramjet flight experiment flight data and CFD calculations compared. AIAA Paper No. 2003-7029.

10. Nair, M., N. Kumar, and S. Saxena. 2003. Reynolds averaged Navier-Stokes based aerodynamic analysis of inlet for a hypersonic research vehicle. AIAA Paper No. 2003-7067.

11. Falempin, F. 1997. French hypersonic program PREPHA - system studies synthesis. 8th ISABE. Chattanooga.

12. Girard, P., M. Calabro, and G. Lauruelle. 1996. The future for reusable launchers: Air-breating or racket propulsion? AAAF Propulsion Conference. France.

13. Serre, L. 1999. Towards a low risk air breathing SSTO program: A continuous robust PREPHA based TSTO. AIAA Paper No. 99-4946.

14. Falempin, F. 2003. The fully reusable launcher: A new concept asking new visions. AIAA Paper No. 2003-7031.

15. Falempin, F., M. Bouchez, L. Serre, C. Bruno, and P. Hendrick. 2005. Airbreathing propulsion for future space launchers - proposal for a minimum R\&T program for Europe. AIAA Paper No. 2005-3362.

16. Bouchez, M., and S. Beyer. 2008. PTAH-SOCAR fuel-cooled composite materials structure. In: Progress in propulsion physics. Eds. L. DeLuca, C. Bonnal, O. Haidn, and S. Frolov. EUCASS advances in aerospace sciences ser. EDP Sciences. 1:62744.

17. Bouchez, M., and S. Beyer. 2006. PTAH-SOCAR fuel-cooled composite materials structure for dual-mode ramjet and liquid rocket engines -2006 status. AIAA Paper No. 2006-8072.

18. Falempin, F., and L. Serre. 2007. LEA flight test program - A first step towards an operational application of high-speed air breathing propulsion. EUCASS 2007.

19. Falempin, F., and L. Serre. 2002. LEA flight test program - A first step towards an operational application of high-speed air breathing propulsion. AIAA Paper No. 2002-5249.

20. Falempin, F., and L. Serre. 2003. LEA flight test program - A first step to an operational application of high-speed air breathing propulsion. AIAA Paper No. 20037031. 
21. Bouchez, M., V. Levine, V. Avrashkov, D. Davidenko, and P. Genevieve. 2000. Air breathing space launcher interest of a fully variable propulsion system. AIAA Paper No. 2000-3340.

22. Roudakov, A., Y. Schickmann, V. Semenov, Ph. Novelli, and O. Fourt. Flight testing an axisymmetric scramjet - Russian recent advances. IAF-93-S.4.485. Gratz.

23. Daniau, E., and F. Falempin. 2007. CDWRE engine developement. EUCASS 2007.

24. Dufour, E., and M. Bouchez. 2002. Semi-emperical and CFD analysis of actively cooled dual mode ramjets AIAA Paper No. 2002-5126. 